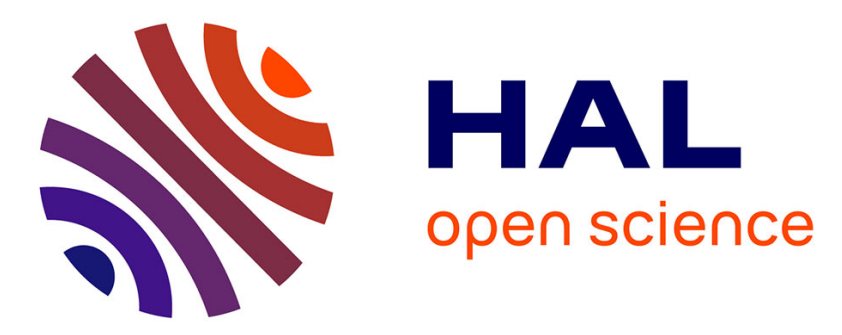

\title{
A Leslie matrix model for Sicyopterus lagocephalus in La Reunion: sensitivity, uncertainty and research prioritization
}

\author{
Marc Artzrouni, Nils Teichert, Thierry A. Mara
}

\section{- To cite this version:}

Marc Artzrouni, Nils Teichert, Thierry A. Mara. A Leslie matrix model for Sicyopterus lagocephalus in La Reunion: sensitivity, uncertainty and research prioritization. Mathematical Biosciences, 2014, 256, pp.18-27. 10.1016/j.mbs.2014.08.005 . hal-01065667

\section{HAL Id: hal-01065667 https://hal.science/hal-01065667}

Submitted on 18 Sep 2014

HAL is a multi-disciplinary open access archive for the deposit and dissemination of scientific research documents, whether they are published or not. The documents may come from teaching and research institutions in France or abroad, or from public or private research centers.
L'archive ouverte pluridisciplinaire HAL, est destinée au dépôt et à la diffusion de documents scientifiques de niveau recherche, publiés ou non, émanant des établissements d'enseignement et de recherche français ou étrangers, des laboratoires publics ou privés. 


\title{
A Leslie matrix model for Sicyopterus lagocephalus in La Réunion: sensitivity, uncertainty and research prioritization
}

\author{
Marc Artzrouni \\ Department of Mathematics (UMR CNRS 5142) \\ University of Pau, 64000 Pau; FRANCE \\ Nils Teichert \\ Association Réunionnaise de Développement de l'Aquaculture \\ ZI Les Sables - BP 16; 97427 Etang-Salé - La Réunion \\ Thierry Mara \\ Department of Physics (EA 4518) \\ University of La Réunion \\ 97715 Saint-Denis, France
}

September 18, 2014

\begin{abstract}
We propose a Leslie matrix model for the population dynamics of $S$. lagocephalus in La Réunion. In order to capture both the amphidromous and the seasonal natures of the species' life history the model has four stages (sea + three river sites) and is periodic. Baseline parameters (age-specific fecundity, spatial dispersion patterns and survival rates) were chosen in such a way that the dominant eigenvalue of the year-on-year projection matrix is 1 . Large uncertainties on the parameter values preclude the use of the model for management purpose. A sensitivity/uncertainty analysis sheds light on the parameters that cause much of the output to vary and that are poorly known: the life expectancy in rivers and the mortality both at river mouths and during the drift of larvae to sea. This work should help researchers understand which factors and parameters need to be better known and estimated before the model can be developed as an accurate management tool.
\end{abstract}

Keywords: Leslie matrix, Sicyopterus lagocephalus, population dynamics, sensitivity, uncertainty.

Corresponding author: marc.artzrouni@univ-pau.fr . 


\section{Introduction}

In La Réunion island the fry of juvenile red-tailed goby (Sicyopterus lagocephalus, Pallas 1770 ) is a much appreciated delicacy, although an expensive one. Known locally as "bichiques" the $3 \mathrm{~cm}$ long juveniles are captured in very high numbers at river mouths as they swim upstream to grow and reproduce $[1,44]$. As a result their numbers have dwindled over the years and the stakes are high [3, 18]. Although S. lagocephalus is widely distributed throughout the Indo-Pacific region, the population of the Mascarene Islands (Mauritius, La Réunion and Rodrigues) largely self-recruits [30]. This highlights the need for local management.

We propose here a population dynamics model of $S$. lagocephalus which aims to shed light on the factors and parameters that influence the species' persistence. The ultimate goal is to provide policymakers with management actions that could help them prevent the decline of the local stock.

Sicyopterus lagocephalus is an amphidromous migratory species $[34,36]$. It has a singular life cycle adapted to the precarious hydrological conditions of rivers where they spawn large number of eggs $[25,31,50]$. Immediately after hatching, larvae drift down to the sea and become "pelagic" as they disperse in the sea $[33,35,51]$. After a few months, the pelagic larvae recruit into river mouths as they move back in freshwater and complete their growth and sexual maturation. They settle in various parts of rivers thanks to their strong climbing abilities which allow them to pass waterfalls up to several meters high, as described in Hawaiian gobies [6, 7].

In addition to living in a challenging natural environment $S$. lagocephalus are subjected to heavy anthropogenic pressures that often impact on aquatic species of tropical islands $[24,39]$. Free movement between freshwater and the marine environment is a key factor for the completion of the life cycle [41]. River mouth closures caused by inadequate river flow management can lead to long-term fish extirpation [32]. A lack of recruitment at the river mouth causes a rapid decrease of adult population in the catchment. The presence of dams along the rivers further limits both the upstream colonization of fish and the 
chances of larvae reaching the sea. In addition, after the marine larval phase, post-larvae are subject to massive fisheries at the river mouths [1, 14, 44].

In Section 2 we detail the Leslie matrix model which describes the population dynamic of the species. Survival, recruitment and fecundity rates are detailed in Section 3. Section 4 discusses the results obtained with a baseline set of parameters. A variance-based sensitivity analysis sheds light on the factors that need further study and helps us prioritize the acquisition of biological knowledge. Results are summarized in the concluding Section 5.

\section{$2 \quad$ Leslie matrix model}

\subsection{The life cycle}

We capture the population dynamics outlined above in a stylized manner by using a multistage cyclical Leslie matrix model for the female population only (Figure 1). Modeling only the female population is standard practice and assumes that the number of males does not affect the females' reproductive ability [10,38]. The stages correspond to the different ecological sites inhabited during the life-cycle. There are four stages: the sea and three river sites.

A one-month time step is chosen because females spawn approximately once a month with a pause during the cooler periods $[14,31,50]$. The eggs hatch about 48 hours after fertilization. As with other Sicydiinae $[2,31]$, free embryos then drift toward the sea in less than a day or two [51]. Because this duration is negligible compared to the one-month time-step, we consider that larvae begin their life at sea. Our data shows that the Pelagic Larval Duration (PLD) extends from 96 to 296 days ( $\approx 10$ months) depending on the time of year the larva hatched [19, 29, 48]. During this period, larvae are subjected to the competing risks of mortality and recruitment: each month a larva can die or survive, with or without recruitment in river mouth.

After recruiting into river mouths post-larvae and juveniles adopt a benthic lifestyle 
and colonize the watershed $[25,26]$. They face competition for habitats as well as added risks of mortality through fishing and predation [25, 26]. If they survive, juveniles settle for their adult period anywhere from the mouth to the upper reaches of the rivers. The exact location and subsequent movements depend on accessibility and the availability of food, reproductive territories and others poorly known factors [18, 26, 49]. We capture these complex migratory patterns in a highly stylized manner by assuming that upon recruitment juveniles settle in one of three defined "river-sites" (indexed 1 to 3): downstream, midstream or upstream. Although recently recruited fish spend a short time in a lower site on the way to their final destination we simplify the migratory movements by assuming that at recruitment they are instantly dispatched to one of the three river-sites. In the absence of detailed information on migrations between sites we also assume that once a fish has reached its settlement site at recruitment it stays there.

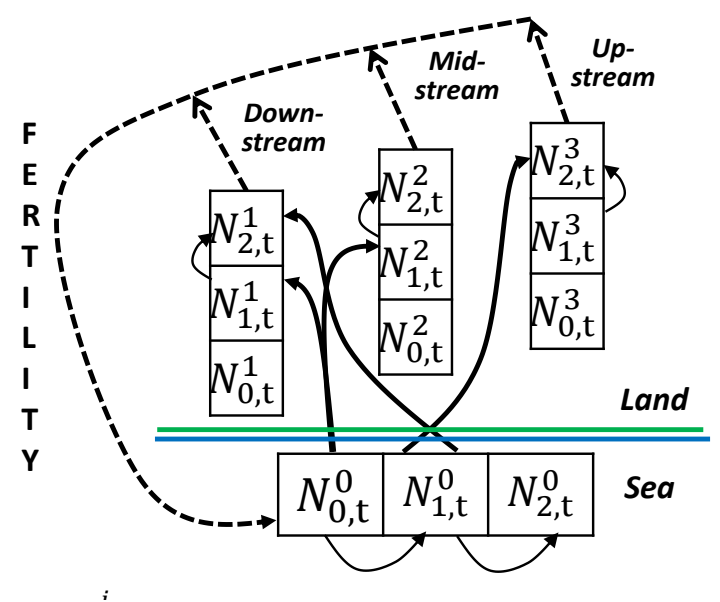

Figure 1: Stylized depiction of the four-site population structure (sea and down-, midand up-stream river destinations). The population of Sicyopterus lagocephalus is assumed for this illustrative example to have only three-age group. After their birth in rivers larvae drift rapidly towards the sea (dotted "fertility" line). They stay a few months at sea and recruit into the next age group (thick arrows) in one of three river sites where juveniles then stay, mature and reproduce. In $N_{i, t}^{k}$ the river sites are indexed by the superscripts $k=1,2,3$ and age groups by the first subscript $i$. Thin arrows represent survival with a transition to the next age group. 


\subsection{The abundance vector}

We let $\mathbf{N}_{\mathbf{t}}^{0}$ be the age-structured larval abundance vector (population at sea with $m_{0}$ larval age groups) at the end of month $t$. The sea is the site indexed 0 . Similarly $\mathbf{N}_{\mathbf{t}}^{\mathbf{k}}$ $(k=1,2,3)$ are the adult abundance vectors in the three rivers sites, each with $m_{k}$ age groups (theoretically there could be different numbers of age groups in different river sites - if for example survival rates differed drastically). Each site-specific abundance vector is of the form

$$
\mathbf{N}_{\mathbf{t}}^{\mathbf{k}}=\left(N_{0, t}^{k}, N_{1, t}^{k}, \ldots N_{m_{k}-1, t}^{k}\right), k=0,1,2,3
$$

When at time $t$ a larva aged $i$ at sea recruits and settle into the $k$ th river site it has "migrated" from the $(i+1)$ st component of $\mathbf{N}_{\mathbf{t}}^{\mathbf{0}}$ into the $(i+2)$ nd component of $\mathbf{N}_{\mathbf{t}+\mathbf{1}}^{\mathbf{k}}{ }^{1}$. The overall abundance vector

$$
\mathbf{N}_{\mathbf{t}} \stackrel{\text { def. }}{=}\left(\mathbf{N}_{\mathbf{t}}^{0}, \mathbf{N}_{\mathbf{t}}^{1}, \mathbf{N}_{\mathbf{t}}^{2}, \mathbf{N}_{\mathbf{t}}^{3}\right)
$$

is obtained by stacking the site-specific vectors and has $\sum_{k=0}^{k=3} m_{k}$ components.

\subsection{Twelve month-specific Leslie matrices}

We will first give the structure of the twelve month-specific Leslie matrices which are used to obtain $\mathbf{N}_{\mathbf{t}+\mathbf{1}}$ on the basis of $\mathbf{N}_{\mathbf{t}}$. These matrices contain survival, recruitment and fecundity rates. The modelling of these rates is detailed in Section 3.

In what follows $\tau$ will represent a month between 1 and 12 and $\mathbf{M}_{\tau}$ is the Leslie matrix with the survival, recruitment and fecundity rates prevailing during month $\tau$. This matrix will be applied to a population vector at the end of the previous month to produce the population at the end of month $\tau$.

\footnotetext{
${ }^{1}$ This means that the first components of the river sites have zero populations. However having these vectors start at age 0 simplifies notations
} 


\subsubsection{Site specific survival matrices}

For each month $\tau=1,2, \ldots, 12$ the within-site matrices of survival rates in site $k$ are

$$
\mathbf{S}_{\tau}^{\mathbf{k}} \stackrel{\text { def. }}{=}\left(\begin{array}{ccccc}
0 & 0 & \cdot & \cdot & 0 \\
s_{1, \tau}^{k} & 0 & \cdot & \cdot & 0 \\
0 & s_{2, \tau}^{k} & 0 & \cdot & 0 \\
\cdot & \cdot & \cdot & \cdot & \cdot \\
0 & 0 & . & s_{m_{k}-1, \tau}^{k} & 0
\end{array}\right), k=0,1,2,3 .
$$

The survival rate $s_{i, \tau}^{k}$ is thus the proportion of fish who at month $\tau$ are aged $i-1$ months and survive within site $k$ to the next month. At sea $(k=0)$ the larvae are subjected to the competing risks of death (or dispersion) and recruitment, which means a possible migration to one of the river sites. In Section 3 we will therefore express these rates $s_{i, \tau}^{0}$ as products of a survival rate multiplied by a probability of absence of recruitment - both of which will depend on the current month $\tau$.

The within river-sites survival rates $s_{i, \tau}^{k}$ for $k>0$ are pure survival rates (no risk of migration) and will not be month-dependent (in this case the $\tau$ is superfluous).

\subsubsection{Site-specific recruitment rates matrices}

The matrices of site-specific recruitment rates from the sea into each one of the river-sites are 


$$
\mathbf{R}_{\tau}^{\mathbf{k}} \stackrel{\text { def. }}{=}\left(\begin{array}{cccc}
0 & 0 & \cdot & 0 \\
r_{1, \tau}^{k} & 0 & \cdot & 0 \\
0 & r_{2, \tau}^{k} & \cdot & \\
\cdot & \cdot & \cdot & \cdot \\
0 & 0 & \cdot & r_{m_{0}, \tau}^{k} \\
0 & 0 & \cdot & 0 \\
\cdot & \cdot & \cdot & \cdot \\
0 & 0 & \cdot & 0
\end{array}\right), k=1,2,3 .
$$

The recruitment rate $r_{i, \tau}^{k}$ is the proportion of larvae at sea aged $i-1$ during the month $\tau$ who will survive an extra month at the end of which they will recruit in mouth and settle into site $k$ - if they have also survived the hazards encountered at the river mouth (fishing, predation, etc.). Both the survival and recruitment rates will depend on $\tau$. Each $\mathbf{R}_{\tau}^{\mathbf{k}}$ thus has $m_{k}$ rows (the number of age groups in the $k$-th site) and $m_{0}$ columns (number of age groups in 0-th site (sea)). Equation (4) assumes that $m_{k}>m_{0}$ which is the case in our application. Indeed the maximum number of months $m_{0}$ spent in the sea is 10 months, whereas the maximum number of months $m_{k}$ a fish lives in the rivers is of the order of one hundred months, as suggested for other Sicydiinae [3, 7, 23].

\subsubsection{Fecundity rates}

The $m_{0}$ by $m_{k}$ matrices with a first row containing the fecundity rates are

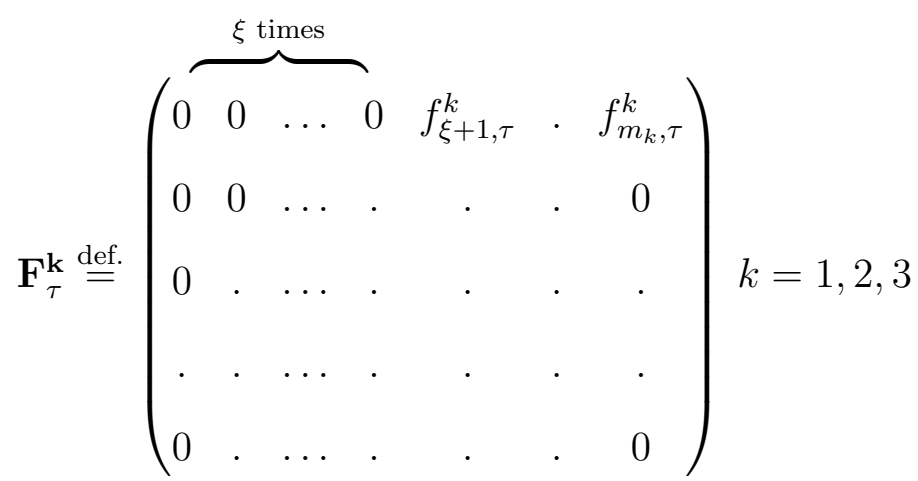


where $f_{i, \tau}^{k}$ is the number of larvae produced in site $k$ the month $\tau$ by a female aged $i$ months. Females do not reproduce before roughly the third month spent in rivers [48]. Because the age in rivers is counted from birth (and not recruitment) we approximate this early period of infertility by specifying an age $\xi$ (from birth) up to which fecundity is 0 (Eq. (5)).

If $\mathbf{0}_{\mathbf{i}, \mathbf{j}}$ denotes the zero matrix with $i$ rows and $j$ columns the 12 month-specific Leslie matrices are obtained by putting together the survival, recruitment, fecundity and zero matrices:

$$
\mathbf{M}_{\tau} \stackrel{\text { def. }}{=}\left(\begin{array}{cccc}
\mathbf{S}_{\tau}^{0} & \mathbf{F}_{\tau}^{1} & \mathbf{F}_{\tau}^{2} & \mathbf{F}_{\tau}^{\mathbf{3}} \\
\mathbf{R}_{\tau}^{1} & \mathbf{S}_{\tau}^{1} & \mathbf{0}_{\mathbf{m}_{1}, \mathbf{m}_{2}} & \mathbf{0}_{\mathbf{m}_{1}, \mathbf{m}_{3}} \\
\mathbf{R}_{\tau}^{2} & \mathbf{0}_{\mathbf{m}_{2}, \mathbf{m}_{1}} & \mathbf{S}_{\tau}^{2} & \mathbf{0}_{\mathbf{m}_{2}, \mathbf{m}_{3}} \\
\mathbf{R}_{\tau}^{3} & \mathbf{0}_{\mathbf{m}_{3}, \mathbf{m}_{1}} & \mathbf{0}_{\mathbf{m}_{3}, \mathbf{m}_{2}} & \mathbf{S}_{\tau}^{3}
\end{array}\right), \tau=1,2, \ldots, 12 .
$$

\subsection{Leslie cyclical recurrence equation}

The cyclical pattern in the Leslie matrices used for the projections will have at its core the (backward) product of the 12 month-specific Leslie matrices from January to December. This product is

$$
M \stackrel{\text { def. }}{=} M_{12} M_{11} \cdots M_{1} \text {. }
$$

Because of the seasonalities we need to know the month $m^{*}$ at which we start a projection with an initial population vector $\mathbf{N}_{\mathbf{0}}$ at the end of month $m^{*}$. The Leslie matrix used to obtain the population $\mathbf{N}_{1}$ at the end of month $m^{*}+1$ will be the one prevailing during month $m^{*}+1$. Therefore the population vector $\mathbf{N}_{\mathbf{1}}$ at month 1 will be $\mathbf{M}_{\mathbf{m}^{*}+\mathbf{1}} \mathbf{N}_{\mathbf{0}}$. Similarly at month 2 the vector $\mathbf{N}_{\mathbf{2}}$ is $\mathbf{M}_{\mathbf{m}^{*}+\mathbf{2}} \mathbf{M}_{\mathbf{m}^{*}+\mathbf{1}} \mathbf{N}_{\mathbf{0}}$ - at least if $m^{*}+2 \leq 12$. More generally, we write any month $t$ as $t=12 t_{1}+t_{2}$ with $0 \leq t_{2}<12$, i.e. $t_{2}$ is $\bmod (t, 12)$, the remainder of the division of $t$ by 12. If $t_{2}>12-m^{*}$ the population vector $\mathbf{N}_{\mathbf{t}}$ is obtained by first multiplying $\mathbf{N}_{\mathbf{0}}$ on the left by the matrices $\mathbf{M}_{\mathbf{k}}$ for $k$ from $m^{*}+1$ to 12 ; then the result is multiplied by $t_{1}$ times the product of all 12 Leslie matrices ( $\mathbf{M}$ of Eq. (7)), and finally by the matrices $\mathbf{M}_{\mathbf{k}}$ for $k$ from 1 to $t_{2}-12+m^{*}$. Recalling that $t$ is 
written as $t=12 t_{1}+t_{2}$ we have

$$
\begin{aligned}
\mathbf{N}_{\mathbf{t}} & =\mathbf{N}_{\mathbf{1 2} \mathbf{t}_{\mathbf{1}}+\mathbf{t}_{\mathbf{2}}}=\mathbf{M}_{\mathbf{t}_{\mathbf{2}}-\mathbf{1 2}+\mathbf{m}^{*}} \mathbf{M}_{\mathbf{t}_{\mathbf{2}}-\mathbf{1 1}+\mathbf{m}^{*}} \cdots \mathbf{M}_{\mathbf{1}} \underbrace{\left(\prod_{i=0}^{i=11} \mathbf{M}_{\mathbf{1 2 - i}}\right) \cdots\left(\prod_{i=0}^{i=11} \mathbf{M}_{\mathbf{1 2 - i}}\right)}_{t_{1} \text { times }} \\
& \times \mathbf{M}_{\mathbf{1 2}} \mathbf{M}_{\mathbf{1 1}} \cdots \mathbf{M}_{\mathbf{m}^{*}+\mathbf{1}} \mathbf{N}_{\mathbf{0}} \\
& =\mathbf{M}_{\mathbf{t}_{\mathbf{2}}-\mathbf{1 2}+\mathbf{m}^{*}} \mathbf{M}_{\mathbf{t}_{\mathbf{2}}-\mathbf{1 1}+\mathbf{m}^{*}} \cdots \mathbf{M}_{\mathbf{1}} \times \mathbf{M}^{\mathbf{t}_{1}} \times \mathbf{M}_{\mathbf{1 2}} \mathbf{M}_{\mathbf{1 1}} \cdots \mathbf{M}_{\mathbf{m}^{*}+\mathbf{1}} \mathbf{N}_{\mathbf{0}} .
\end{aligned}
$$

If $m^{*}=12$ then $\mathbf{N}_{\mathbf{0}}$ is multiplied directly by the $t_{1}$ products of 12 matrices then by the remaining $t_{2}$ matrices. If $t_{2} \leq 12-m^{*}$ we obtain in a similar fashion

$$
\mathbf{N}_{\mathrm{t}}=\mathrm{N}_{12 \mathrm{t}_{1}+\mathrm{t}_{2}}=\mathrm{M}_{\mathrm{t}_{2}+\mathrm{m}^{*}} \mathrm{M}_{\mathrm{t}_{2}-1+\mathbf{m}^{*}} \cdots \mathrm{M}_{1} \times \mathrm{M}^{\mathrm{t}_{1}} \times \mathrm{M}_{12} \mathrm{M}_{11} \cdots \mathrm{M}_{\mathrm{m}^{*}+\mathbf{1}} \mathrm{N}_{\mathbf{0}}
$$

If the matrix $\mathbf{M}$ is primitive (i.e. there exists $p$ such that $\mathbf{M}^{\mathbf{p}}>\mathbf{0}$ ) then for a large $t_{1}$ we have by Perron-Frobenius that $\mathbf{M}^{\mathbf{t}_{1}} \sim \lambda^{t_{1}}$ where $\lambda$ is the (positive) dominant eigenvalue of $\mathbf{M}$. For a fixed remainder $t_{2}$, initial population and months $\mathbf{N}_{\mathbf{0}}$ and $m^{*}$ there exists a vector $\mathbf{V}\left(\mathbf{N}_{\mathbf{0}}, t_{2}, m^{*}\right)$ such that for a large $t_{1}$ we have

$$
\mathbf{N}_{\mathbf{1 2}_{1}+\mathbf{t}_{\mathbf{2}}} \sim \lambda^{t_{1}} \mathbf{V}\left(\mathbf{N}_{\mathbf{0}}, t_{2}, m^{*}\right)
$$

This expression shows that year-on-year all age groups grow at the same annual rate $\lambda-1$, although with a $\lambda^{t_{1}}$ that is a multiplied by a vector $\mathbf{V}\left(\mathbf{N}_{\mathbf{0}}, t_{2}, m^{*}\right)$ which depends on the month being considered (as well as the initial population).

\section{Survival, recruitment and fertility models}

\subsection{Pelagic survival without recruitment}

\subsubsection{Model}

Before deriving the pelagic survival rates $s_{i, \tau}^{0}$ of Eq. (3) which take into account the risk of recruitment, we need to specify a survival model in the absence of this risk. This survival 
at sea depend on age and the current month $\tau$.

We will capture both aspects multiplicatively by assuming that month-to-month survival rates are the product of a baseline age-specific value multiplied by a seasonal factor depending on the month.

1. Baseline survival. Very little is known on mortality at sea, other than the fact of an extremely low survival by the time of recruitment (which we conflate with dispersion at sea: a larva that either dies or disappears has no chance of making it to shore) [35]. This survival rate at the end of larval duration is of the order of $10^{-5}$ or less as commonly observed for small pelagic larvae [20,21]. We also assume that the hazard rate is extremely high initially and decreases as larvae grow [21]. A Weibull distribution with a shape parameter $\gamma$ less than 1 captures this pattern because its hazard rate is of the form $x^{\gamma-1}$ where $x$ is age (An "extremely high" initial hazard rate is thus modelled as a hazard rate approaching $+\infty$ for an age $x \approx 0$ ).

Because the standard parameters for the Weibull distribution are difficult to interpret, we will parametrize the distribution with survival rates $\sigma_{1}$ and $\sigma_{2}$ specified at two points in time $t_{1}$ and $t_{2}$. If we define

$$
\gamma \stackrel{\operatorname{def} .}{=} \frac{\ln \left(\frac{\ln \left(\sigma_{2}\right)}{\ln \left(\sigma_{1}\right)}\right)}{\ln \left(\frac{t_{2}}{t_{1}}\right)} ; \alpha \stackrel{\text { def. }}{=} \frac{t_{2}}{\ln \left(1 / \sigma_{2}\right)^{1 / \gamma}}
$$

then the Weibull survival rate with the required properties is

$$
S(x) \stackrel{\text { def. }}{=} e^{-(x / \alpha)^{\gamma}}
$$

The baseline survival rate from age $i-1$ to $i$ is then $S(i) / S(i-1)$. For the hazard rate

$$
h(x) \stackrel{\text { def. }}{=} \frac{\gamma}{\alpha}\left(\frac{x}{\alpha}\right)^{\gamma-1}
$$

to be a decreasing function of age $x$ the shape parameter $\gamma$ of Eq. (11) must be less than 1. 
2. Seasonal adjustment. The dependence on the month $\tau$ comes from the fact that survival rates are higher with lower temperature, as demonstrated in marine larvae [20]. The temperature depends on the month with a fairly simple seasonal pattern. A periodic annual pattern for the temperature $T(\tau)$ at month $\tau$ is well captured by a periodic regression [5] of the form

$$
T(\tau) \stackrel{\text { def. }}{=} b_{0}+b_{1} \sin \left(\frac{2 \pi \times \tau}{12}\right)+b_{2} \cos \left(\frac{2 \pi \times \tau}{12}\right)
$$

In order to model the effect of temperature we will need the minimum and maximum temperatures over the 12 months:

$$
t_{\min }=\min _{1 \leq m \leq 12} T(m), t_{\max }=\max _{1 \leq m \leq 12} T(m) .
$$

We next define the parameter $\kappa$ equal to the fraction by which the survival $S(i) / S(i-1)$ rate increases (or decreases) when the temperature reaches its minimum $t_{\min }$ (or maximum $\left.t_{\max }\right)$. The survival rate $\sigma(i, \tau)$ of a larva aged $i$ months at month $\tau$ is now the baseline survival rate $S(i) / S(i-1)$ multiplied by an affine function of $T(\tau)$ with the right properties:

$$
\sigma(i, \tau) \stackrel{\text { def. }}{=} \frac{S(i)}{S(i-1)} \times\left(1-\kappa-\frac{2 t_{\max } \kappa}{t_{\min }-t_{\max }}+\frac{2 \kappa}{t_{\min }-t_{\max }} T(\tau)\right)
$$

Indeed one easily checks that the minimum (or maximum) survival rate $S(i) / S(i-1) \times$ $(1-\kappa)($ or $S(i) / S(i-1) \times(1+\kappa))$ are obtained at the warmest (or coolest) month when the temperature $T(\tau)$ is $t_{\max }\left(\right.$ or $\left.t_{\min }\right)$.

\subsubsection{Baseline parameter values}

Numerical values for the parameters $b_{0}, b_{1}$ and $b_{2}$ of the modelled temperature of Eq. (14) are found by routine least square minimization (Table 1 brings together these and all other parameter values). Data were Sea Surface Temperature (SST, in Celsius degree) between 2001 and 2011 from an analysis of NOAA satellite images (0.5 degree resolution) 
on the Reunion station, France $\left(21^{\circ} 5^{\prime} \mathrm{S}, 55^{\circ} \mathrm{E}\right)$ [37]. The fraction $\kappa$ is taken equal to 0.2 which reflects a $40 \%$ decrease from the coldest to the warmest months. With this value the modelled peak recruitment months coincided with the known periods of maximum larvae abundance at the river mouths (i.e. from September to December). The survival parameters $\sigma_{1}$ and $\sigma_{2}$ used to specify the baseline Weibull were chosen at times $t_{1}=2$ months (roughly the highest mortality period) and $t_{2}=7$ months (roughly the longest pelagic duration). More on the choice of these survival rates in the Discussion section.

\subsection{Recruitment and site-dispersion models}

\subsubsection{Model}

In the absence of the risk of mortality/dispersion at sea the time until a larva moves back into freshwater is a random variable $R_{m b}$ which depends on the month of birth $m b^{2}$ [48], as observed in others Sicydiinae [4,45]. For a larva aged $i$ months at month $\tau$ the month of birth is a simple arithmetic function $m b(i, \tau)$ of $i$ and $\tau$ :

$$
m b(i, \tau)=\left\{\begin{array}{ll}
\bmod (\tau-i-1,12)+1 & \text { if } \tau-i-1 \geq 0 \\
12-\bmod (i-\tau, 12) & \text { otherwise }
\end{array} .\right.
$$

For each one of the 12 possible months of births $m b$ we define the cumulative distribution function $F_{m b}(x)$ of $R_{m b}$. We will need the discretized hazard of reaching a river mouth for a fish aged $i$ at month $\tau$. This hazard is the probability $\rho_{i, \tau}$ of the event occurring during the next month conditionally on it not having occurred yet:

$$
\rho_{i, \tau} \stackrel{\text { def. }}{=} \frac{F_{m b(i, \tau)}(i+1)-F_{m b(i, \tau)}(i)}{1-F_{m b(i, \tau)}(i)} .
$$

The pelagic survival (at sea) $s_{i, \tau}^{0}$ of Eq. (3) for $k=0$ must incorporate the probability

\footnotetext{
2 "Recruitment", formulated through the recruitment rates $r_{i, \tau}^{k}$ of Eq. (4) will occur when a larva reaches a river mouth and survives the various risks of predation and fishing during that event and chooses a river-site.
} 
$1-\rho_{i, \tau}$ that the larva does not reach a river mouth that month:

$$
s_{i, \tau}^{0} \stackrel{\text { def. }}{=} \frac{\sigma(i+1, \tau)}{\sigma(i, \tau)}\left(1-\rho_{i, \tau}\right)
$$

where the $\sigma$ 's are those of Eq. (16).

The rates at which larvae return in freshwater are $\rho_{i, \tau} \sigma(i+1, \tau) / \sigma(i, \tau)$. In order to have the desired recruitment rates we incorporate the risk of mortality at recruitment (through fishing, predation or competition): $\varphi_{\tau}$ is the survival rate at month $\tau$ from those combined threats at recruitment. This dependence on the month $\tau$ can reflect seasonal changes in the intensity of fishing - although in our numerical application the $\varphi_{\tau}$ 's will be equal. We also define the vector $\theta=\left(\theta_{1}, \theta_{2}, \theta_{3}\right)$ of probabilities of larvae choosing each one of the three river-sites $\left(\Sigma \theta_{i}=1\right)$.

The recruitment rate $r_{i, t}^{k}$ into site $k \geq 1$ for a fish aged $i$ at time $t$ (Eq. (4)) is now obtained by combining the return rate in freshwater with survival at the river mouth and the choice of river site:

$$
r_{i, \tau}^{k} \stackrel{\text { def. }}{=} \frac{\sigma(i+1, \tau)}{\sigma(i, \tau)} \rho_{i, \tau} \varphi_{\tau} \theta_{k}, k=1,2,3
$$

\subsubsection{Baseline parameter values}

The distribution of the age-at-recruitment $R_{m b}$ conditionally on the month of birth $m b$ was obtained by measuring the number of growth rings in the otoliths (i.e. structure of the inner ear of fish) of 396 post-larvae sampled at river mouths on 14 days between November 2006 and March 2009 [48]. Although sample sizes for each month of birth were small, the distributions were roughly normal, i.e.

$$
R_{m b} \sim \mathcal{N}\left(\mu_{m b}, \sigma_{m b}\right) m b=1,2, \ldots, 12
$$

with the 12 estimated mean and standard deviations given in Table 1.

The survival rates $\varphi_{\tau}$ when recruitment takes place the month $\tau$ are all taken equal 
to 0.05 . This value is consistent with survival rate at settlement observed in recruits of marine reef species, such as Epinephelus merra (Serranidae) in La Réunion coral reefs $[13,28]$. We did not include seasonal effect of fisheries pressure due to the lack of reliable data. The spatial distribution of $S$. lagocephalus is strongly influenced by the river gradient $[18,49]$. Data from the Ichthyological Monitoring Network of the Reunion Island (online data $^{3}$ ) shows that around $55 \%$ of settled populations were found downstream, whereas $35 \%$ and $10 \%$ were observed respectively in the midstream and upstream sites [40]. The probabilities of river-site choice $\theta_{i}$ were thus taken equal to $0.55,0.35$ and 0.10 .

\subsection{River survival (adult period)}

\subsubsection{Model}

In the absence of precise information we will assume constant death rates in each one of the three sites (exponential survival times, which depend on the river-site). We will parametrize the distribution with life expectancies after recruitment $e_{1}, e_{2}, e_{3}$ months, for each one of the three river-sites. One-month survival rates thus depend only on the site:

$$
s_{i, \tau}^{k} \stackrel{\text { def. }}{=} \exp \left(-e_{k}^{-1}\right) \approx 1-e_{k}^{-1}, k=1,2,3
$$

\subsubsection{Baseline parameter values}

Survival in rivers is known as poorly as larval pelagic survival. In the absence of more precise information we took a life expectancies $e_{i}$ of 24 months for all three sites. This is consistent with the 2 to 4 years of river life observed for Sicyopterus stimpsoni in Hawaiian Islands [7] and the 6 to 7 years of Sicyopterus japonicus in Japan [23].

\footnotetext{
${ }^{3}$ http://banquededonnees.eaureunion.fr/bdd/
} 


\subsection{Fecundity}

\subsubsection{Model}

Fecundity rates are the numbers of female eggs produced each month by a female fish. As observed for others Sicydiinae, these rates drop to 0 during colder months of the year $[15,23,31]$. These months depend on the altitude of each one of the river-sites $[14,50]$. We thus define three vectors $Z_{1}, Z_{2}, Z_{3}$ containing the zero fertility months for each site. For example $Z_{1}=(8,9,10)$ means that in the downstream river-site fertility falls to 0 from August to October.

Fecundity rates increase then level off as fish age. A logistic ("S-shaped") function $F(i)$ captures this pattern. We parametrize $F(i)$ with i) the minimum and maximum values of these fecundity rates $f_{\min }$ (for $\left.x \rightarrow-\infty\right)$ and $f_{\max }$ (for $x \rightarrow+\infty$ ), ii) the age $a_{\text {inf }}$ at which the fecundity has its point of inflection; and iii) the value $d_{\text {inf }}$ of the derivative of the fecundity at the point of inflection. The logistic function parametrize in this way is

$$
F(i) \stackrel{\text { def. }}{=} f_{\min }+\frac{f_{\max }-f_{\min }}{1+\exp \left(\frac{4 d_{i n f}\left(i-a_{i n f}\right)}{f_{\min }-f_{\max }}\right)}
$$

After hatching, larvae are subjected to a risk of mortality as they drift toward the sea. In order to capture this effect we will multiply the logistic function by site-specific drift survival rates $\eta_{k}$. The site-specific fecundity rates of Eq. (5) in the three sites are then

$$
f_{\tau}^{k}=\left\{\begin{array}{ll}
0 & \text { if } \tau \in Z_{k} \text { or } \tau \leq \xi \\
F(\tau) \eta_{k} & \text { otherwise }
\end{array}, k=1,2,3 ; \tau=1,2, \ldots, m_{k}\right.
$$

where $Z_{k}$ is the set of months during which fertility falls to zero in site $k$ and $\xi$ is the age up to which fecundity is 0 , as discussed in Section 2.3.3. Given the absence of major obstacles on the river-ocean corridor we consider that mortality is negligible during the rapid downward drift of larvae toward the sea. In the absence of precise information we assume this to be the case regardless of the river-site of birth. We thus assume a survival rate $\eta_{k}$ equal to 1 for each river site. The $f_{\tau}^{k}$ 's are effective fecundity rates in the sense 
that they give numbers of larvae that make it to sea.

\subsubsection{Baseline parameter values}

The logistic model was fitted using a relationship between age and size [14] then a relationship between size and fertility [50]. The function $F(x)$ becomes positive at age $x>3.763$ months and fits the data well. The negative values for ages below 3.763 mo. are not a problem because there is no fertility before $\xi$ months and we are setting $\xi=9$. The months during which fertility fall to zero $Z_{1}, Z_{2}$ and $Z_{3}$ are given in Table 1 [50].

\section{Results}

\subsection{Dynamics}

Our goal is not to reproduce a plausible trajectory or projection of the age-specific population of $S$. lagocephalus. This is because the real population is not in any sort of stable state - i.e. not even in the year-on-year sense of the annualized Leslie matrix model represented by the product $\mathbf{M}$ of the 12 monthly matrices (Eq.(7)). Indeed there are stochastic environmental changes which affect fecundity and survival rates, thus precluding any form of stability. We believe there may also be density-dependent mechanisms by which the survival rate at recruitment $\varphi_{\tau}$ decreases during the months when large numbers of juveniles arrive at the river-mouths. This negative feedback reflects larger natural mortality in high density conditions and enhanced opportunistic fishing efforts at work when there are more juveniles to be caught. Even if we were to envisage a stochastic model with these feedbacks such a model would be difficult to calibrate because there is little data on these processes.

Despite environmental and other fluctuations and hazards the population of S. lagocephalus has maintained itself over the decades and centuries. For this reason the numerical values given above for the survival rates both at sea and in the rivers (which are the parameters with the largest uncertainties) were chosen in such a way that they produced 
a dominant eigenvalue 1 - which is a stylized expression of a population in a long-term equilibrium. Implausible values for survival rates chosen in this way would have alerted us to problems in the model specifications. Still, we do not claim that "plausible" means "accurate". For example a life expectancy of 24 months in rivers may be too small, although it does not contradict the fact that a few relatively old fish have been observed. Indeed an exponential distribution with a 24-month average still means that $8 \%$ of fish live more than 5 years after entered in river $(\exp (-60 / 24)=0.082)$.

Having specified the model with plausible parameters (Table 1) leading to a $\lambda$ equal to 1 , we took an arbitrary (and wholly unrealistic) initial population of 1 for the first five age groups and 0 for others. We started the projection in January.

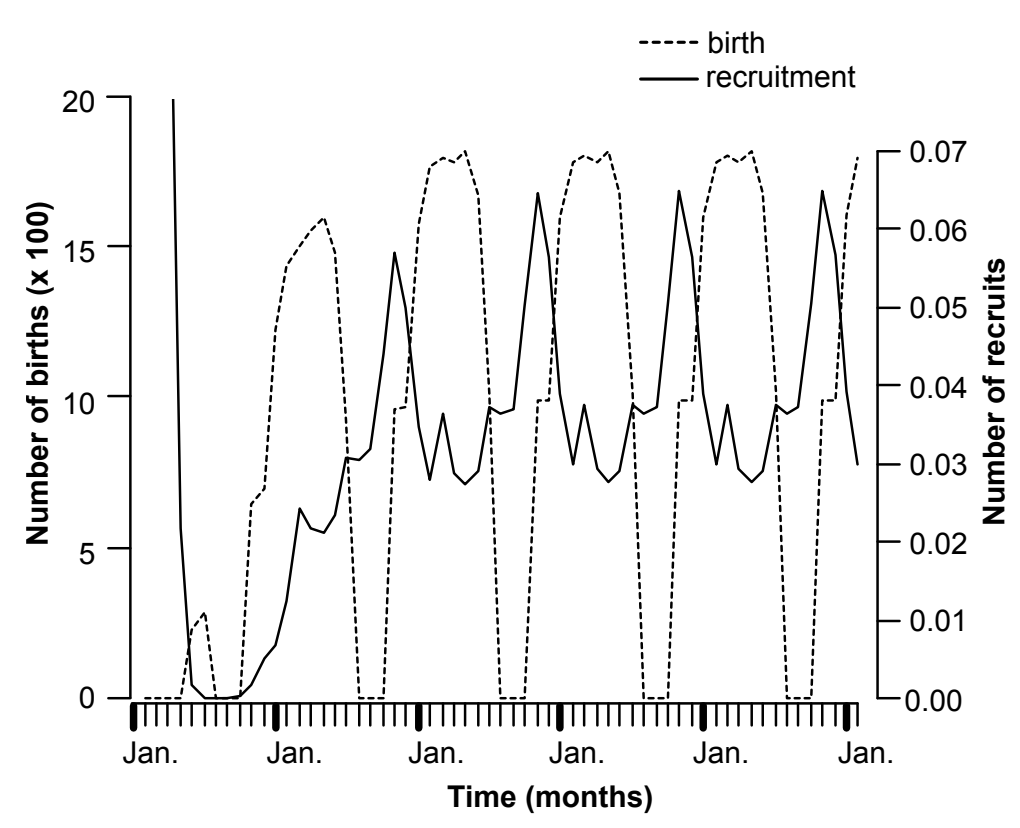

Figure 2: Projection of the population dynamics model of Sicyopterus lagocephalus showing the number of births and the number of recruits at the river mouth.

In order for the matrix $\mathbf{M}$ of (7) to be primitive we need to delete the components of the river-sites population vectors that remain 0 (see footnote in Section 2.2) as well as the corresponding columns of $\mathbf{M}$. Notwithstanding the unrealistic initial population as well as the size and complexity of the model, the population then converged in only two years (24 iterations) to its stationary state (Figure 2). The model reproduces seasonal patterns in good agreement with the periods of high recruitment between September and 
December. These periods are well known locally because they coincide with high levels of fishing at the river mouths [44]. Known smaller recruitment "bursts" between March and July also appear in the model. Zero births between August and September reflect the fact that during those months fertility rates are zero in all three sites (Figure 2).

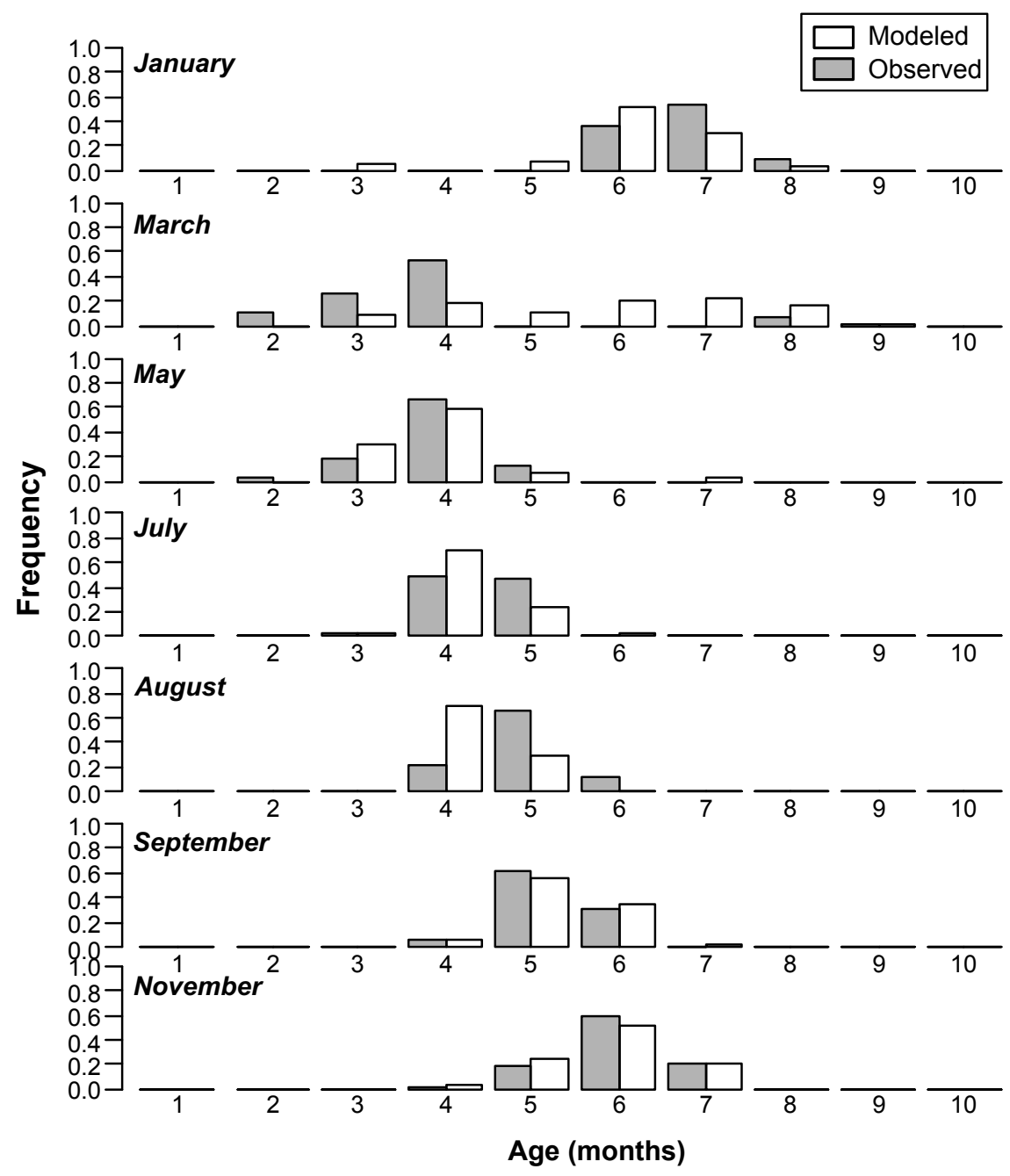

Figure 3: Distribution of pelagic larval duration (duration at sea) by month of recruitment(modeled and observed). Except for March and August the model approximates observed patterns at least crudely.

Field work has produced data on the distribution of Pelagic Larval Duration (PLD, duration at sea) by month of recruitment, for seven of the 12 months in the year [48]. These data can be compared with the model's corresponding outputs (Figure 3). The figure shows a good agreement between modelled and observed values, except in March and August. In March the observed durations are in the 2 to 4 and 8 to 9 months 
range while the modelled ones are more spread out. In August there is a one-month shift between the two distributions. We can see in Figure 3 that starting in March the distribution of PLD shifts to the right with each month of recruitment. This increasing duration is caused by the decreasing temperature encountered by larvae in the marine environment.

We have achieved a first goal of devising a model with plausible parameter values compatible with a $\lambda$ equal to 1 . Our second goal is to assess the sensitivity of the model to the various parameters. This information will help biologists identify the parameters that need to be estimated more accurately.

\subsection{Sensitivity analysis}

\subsubsection{The linear approximation}

There are considerable uncertainties concerning the values of the model's parameters and their impact on the model. Before the model can be used with some confidence as a management/planning tool we therefore need to perform a sensitivity analysis of the model's output. In Leslie matrix models the output is the dominant eigenvalue $\lambda$ of the projection matrix. In the simple situation of an unchanging Leslie matrix and a single site there are detailed results on the sensitivity of $\lambda$ to the entries of the matrix, considered the model's parameters [10]. Sensitivity results are also available for density-dependent models [11], periodic models [27] and in situations where populations are classified by age and state [11]. These results rest on the linear nature of the models and ignore interaction between parameters in addition to being mostly local.

The present situation is more complex with a stage (or state)-classified model and periodically changing matrices. In addition we want a sensitivity analysis not in terms of the entries of the matrices but in terms of the biological parameters used to define these entries. This entails non-linear relationships from the parameters $\mathbf{p}$ to the product $\mathbf{M}$ of 12 Leslie matrices (Eq. (7)) and to the dominant eigenvalue $\lambda(\mathbf{p})$ of $\mathbf{M}$. We thus have a complex non-linear system and choose to use variance-based methods by which we can 
assess more globally the relative contribution of each parameter to the output's variance $[8,17,46]$. These variance-based methods have been used extensively by physicists and engineers $[43,47]$ but less so by life scientists (see however $[9,16]$ and references therein).

In order to reflect the uncertainty concerning their values the model's parameters $\mathbf{p}=\left(p_{i}\right)$ are considered random variables. They can for example be normally or uniformly distributed with the baseline values used above as expected values. The goal is to write the variance of $\lambda(\mathbf{p})$ as a sum of terms that can be interpreted and can shed light on the relative contribution of each parameter to the variance.

We start off with the Sobol decomposition of the function $\lambda(\mathbf{p})$ written as a sum of square integrable functions of an increasing number of the parameters [46]:

$$
\lambda(\mathbf{p})=\lambda_{0}+\sum_{i=1}^{i=k} \lambda_{i}\left(p_{i}\right)+\sum_{j>i} \lambda_{i j}\left(p_{i}, p_{j}\right)+\cdots+\lambda_{1 \ldots k}\left(p_{1}, p_{2}, \ldots, p_{k}\right)
$$

Although $\lambda(\mathbf{p})$ is not a linear function of the parameters it is customary to test whether the model might be approximately linear, at least when parameters do not vary too much. In this case the calculations are simpler. A linear approximation can be justified for biological models if parameters are not allowed to vary too much and have unambiguously monotone effects, e.g. an increase in fertility rates or survival rates both increase $\lambda(\mathbf{p})$. A linear model means that the Sobol decomposition is of the form

$$
\lambda(\mathbf{p})=a_{0}+\sum_{j=1}^{j=k} a_{j} \times\left(p_{j}-E\left(p_{j}\right)\right)
$$

Because the $p_{j}$ 's are independent we have

$$
\operatorname{Var}(\lambda(\mathbf{p}))=\sum_{j=1}^{j=k} a_{j}^{2} \operatorname{Var}\left(p_{j}\right)
$$

The first-order variance-based sensitivity index is then defined as

$$
S_{j} \stackrel{\text { def. }}{=} \frac{a_{j}^{2} \operatorname{Var}\left(p_{j}\right)}{\operatorname{Var}(\lambda(\mathbf{p}))}, j=1,2, \ldots, k
$$


which is the fractional contribution of the $j$ th parameter to the overall variance $\operatorname{Var}(\lambda(\mathbf{p}))$. The sum $\sum_{i} S_{i}$ is then 1 or approximately 1 if the model is approximately linear. We can interpret $S_{i}$ as the expected amount by which the variance of $\lambda$ will be reduced if we know the true value of $p_{i}$. This is of particular interest for our purpose as we wish to prioritize future research in order to improve the reliability of our model. Such an approach is called Factor Prioritization [42].

Given that

$$
\operatorname{Cov}\left(\lambda(\mathbf{p}), p_{i}\right)=\operatorname{Cov}\left(a_{0}+\sum_{j=1}^{j=k} a_{j} \times\left(p_{j}-E\left(p_{j}\right)\right), p_{i}\right)=a_{i} \operatorname{Var}\left(p_{i}\right)
$$

we have

$$
\begin{aligned}
S_{i} & =\frac{a_{i}^{2} \operatorname{Var}\left(p_{i}\right)}{\operatorname{Var}(\lambda(\mathbf{p}))} \\
& =\frac{\operatorname{Cov}\left(\lambda(\mathbf{p}), p_{i}\right)^{2}}{\operatorname{Var}(\lambda(\mathbf{p})) \operatorname{Var}\left(p_{i}\right)}=\rho_{i}^{2}
\end{aligned}
$$

where $\rho_{i}$ is the coefficient of correlation between the output $\lambda(\mathbf{p})$ and the $i$-th parameter $p_{i}$.

The squared value of the Pearson correlation coefficient (CC) is therefore an estimator $\hat{S}_{i}$ of $S_{i}$ when the model is linear. We then consider a sample of $n$ values of each parameter, i.e. $\mathbf{p}_{\mathbf{i}}=\left(p_{1 i}, p_{2 i}, \ldots, p_{n i}\right)$ for $i$ going from 1 to $k$, the number of parameters. We let $\boldsymbol{\lambda}=$ $\left(\lambda_{1}, \lambda_{2}, \ldots, \lambda_{n}\right)$ be the corresponding $n$-dimensional vector of outputs, i.e. the dominant eigenvalues. We then have

$$
\hat{S}_{i}=\hat{\rho}_{i}^{2}=\frac{\left(\sum_{j=1}^{n}\left(p_{j i}-\overline{\mathbf{p}}_{i}\right)\left(\lambda_{j}-\overline{\boldsymbol{\lambda}}\right)\right)^{2}}{\sum_{j=1}^{n}\left(p_{j i}-\overline{\mathbf{p}}_{i}\right)^{2} \times \sum_{j=1}^{n}\left(\lambda_{j}-\overline{\boldsymbol{\lambda}}\right)^{2}}
$$

where the horizontal bars indicate empirical means of the corresponding samples. 


\subsubsection{Numerical results}

The $k=43$ parameters listed in Table 1 are assumed to be uniformly distributed with a range of $\pm 20 \%$ around their baseline values. This way no parameter is favoured. Because the scale in the seasonal variations in pelagic survival is not well known we include in the sensitivity analysis the fractional seasonal increase (or decrease) in survival $\kappa$. Because the seasonal variations in pelagic survival are qualitatively well known the parameters of the periodic regression of temperature are considered fixed. The discrete-value parameters (i.e. the beginning and ending months of the reproductive periods) are taken equal to their baseline value minus 1 , their baseline values, and the baseline value plus 1 with equal probabilities $1 / 3$.

A latin hypercube sample of size $n=256$ is employed to generate the sample. For each trial $\mathbf{p}_{\mathbf{j}}=\left(p_{j 1}, \ldots, p_{j k}\right), j=1, \ldots, n$, the model is run and $\lambda\left(\mathbf{p}_{\mathbf{j}}\right)$ computed. The Pearson correlation coefficients are then estimated from Eq. (32). The Pearson correlation coefficients between the outputs $\lambda(\mathbf{p})$ and the parameters are given in Table 1 and range from -0.19 to 0.58 . The signs of the CCs are consistent with the expected effects of the parameters. For example the life expectancy $e$, the maximum fertility $f_{\max }$, the probability of reaching the sea $\eta$ and the survival rate at recruitment $\varphi_{\tau}$ are positively correlated with the output. Conversely, the age at fertility inflection $a_{\text {inf }}$ and the durations of nonreproductive periods $Z_{k}$ are negatively correlated with $\lambda(\mathbf{p})$. The linear approximation is justified a posteriori because $\sum_{i} \hat{\rho}_{i}^{2}=0.982$ is close to 1 and the square values of the CCs can then be used as estimators of $S_{i}$.

\subsubsection{Pooled sensitivity}

Given the quasi-linear behaviour of our model, it is of interest to pool (i.e. sum) squared CCs within biologically meaningful groups - specifically the seven parameter groups defined in bold letters in Table 1. The sum of squared CCs within each group is

$$
\rho_{\text {group }}^{2} \stackrel{\text { def. }}{=} \sum_{i \in \text { group }} \hat{\rho}_{i}^{2}
$$


and represents the percentage in $\lambda$ 's variation that is due to the parameters in the group. The life expectancy of fish within rivers ("River Survival group" - RSG) is the most important group and explains $\rho_{R S G}^{2}=34.1 \%$ of the output variations. The "Age-specific fecundity" group explains $\rho_{A S F}^{2}=17.8 \%$ of the variation. The "Recruitment Survival and

Site Dispersion" comes in third at $\rho_{R S S D}^{2}=12.8 \%$. These three groups capture almost two thirds of the total variation $(64.7 \%)$. More surprisingly and despite the extremely high larval mortality, the pelagic survival $(6.5 \%)$ and pelagic duration at sea $(3.4 \%)$ are the least influential parameter groups. Three parameter groups are in the 10 to $20 \%$ range (Figure 4 incorporates the uncertainty on the parameters and has these percentages on the $x$-axis). In the next section we argue that a sensitivity analysis goes hand in hand with an uncertainty analysis.

\subsection{Uncertainty vs. sensitivity analysis}

An Uncertainty Analysis (UA) usually complements a Sensitivity Analysis (SA). Indeed there is a relatively recent consensus that UA "quantifies the variability of the output caused by the incomplete knowledge or misspecification of the modeller" while SA "aims at establishing the relative importance of the input factors involved in the model" ([9] pp. 168-169). Both analyses dovetail however. Indeed, our concern until now has been with a sensitivity analysis aimed at prioritizing future research in terms of identifying the parameters that have the greatest impact on the output variability - with a view toward improving the precision of the corresponding parameter. But the need for this improvement depends on the level of "certainty" on the parameters. If a parameter has a great influence on the variance but is already well known, there is no need to improve its estimate. The same holds if a parameter is very "uncertain" but contributes little to the variance.

A detailed quantified uncertainty analysis is beyond the scope of this paper. However some parameters (or groups thereof) are better known than others. For example fecundity rates and pelagic durations are known fairly accurately whereas we do not even know 
orders of magnitudes for survival rates, both at sea and in the rivers. It is then of interest to cross-classify, however crudely, the groups of parameters according to levels of uncertainty and levels of sensitivity. Uncertainty is assessed through our own subjective "expert opinion" as being low, medium or high. Sensitivity for each one of the seven

parameter groups is measured by the pooled $\rho_{\text {group }}^{2}$ 's discussed in Section 4.2.3.

Through river survival and fecundity, Figure 4 shows that it is the river life stage that has the most influence on the model. Perhaps this is because these factors are at play during years, as opposed to recruitment which is a one-off, instantaneous event, or pelagic duration which affects only the first few months of the life cycle. River survival (i.e. life-expectancy in river) is thus the single most critical parameter in view of its large influence on the model and large uncertainty - this parameter should therefore be a priority for future research.

Both the sensitivity and uncertainty on fecundity is substantially smaller than that on river survival, but is still far from negligible. A logistic function is a highly simplified model for a fecundity that increases with age. The timing and steepness of the inflection rely on delicate relationships between size, age and fecundity which can also depend on the river site due to differences of environmental conditions - a dependence not accounted for in our model. More generally fecundity, as well as drift and recruitment survival rates depend on environmental and anthropomorphic factors that are both poorly understood and documented.

If the river parameters are the most sensitive and uncertain, Figure 4 shows that the pelagic duration and survival are the least sensitive factors, but have very different uncertainties: it is low for pelagic duration (in the absence of mortality) while the pelagic survival is extremely uncertain.

\section{Conclusion}

Modelling the population dynamics of species subjected to fluctuating conditions in a multi-stage environment is a challenge - particularly when little data is available. The 


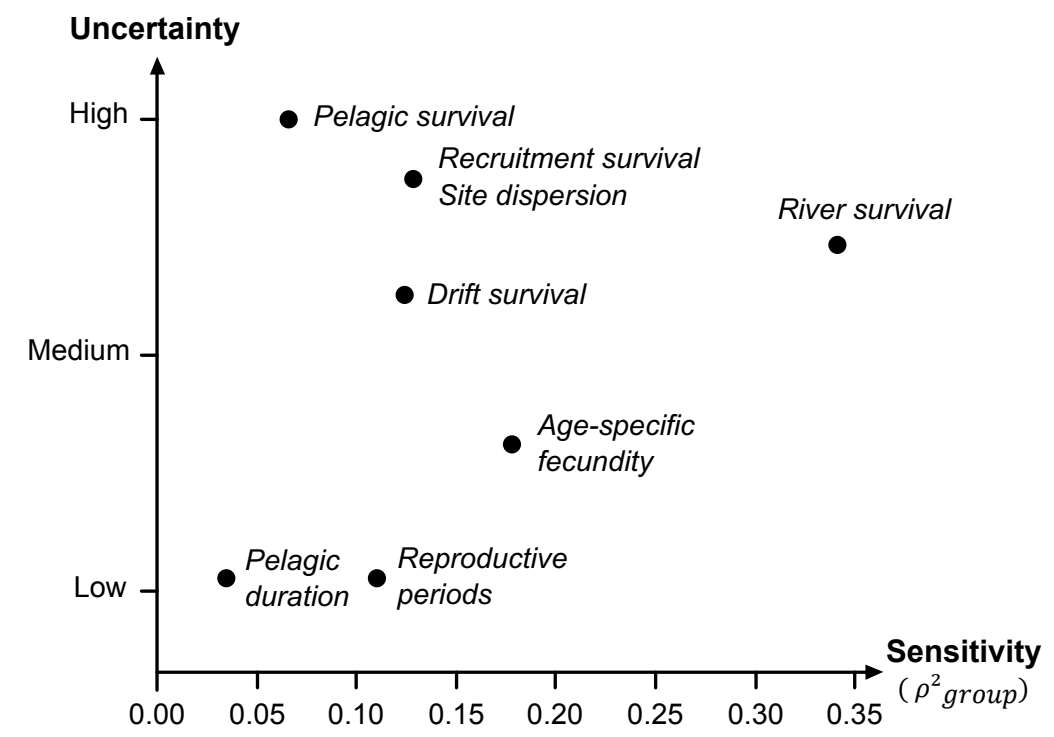

Figure 4: Rough cross-classification of the seven parameter groups by their pooled sensitivity $\rho_{\text {group }}^{2}$ (Eq. (33)) and our "expert opinion" estimates of the uncertainty on each group.

challenge is enhanced by the extreme nature of the fecundity rates (tens of thousands a month) and of the survival rates (one in a hundred thousand reaches the age of reproduction). These extreme rates reflect challenging natural conditions of tropical islands which affect food availability, competition for habitat, predation etc. To these natural hazards one has to add anthropogenic factors such as the intensive fishing at river mouths and poaching. Dams and weirs can affect the movement of migratory species and compromise habitats diversity.

Our model aggregates many natural and anthropogenic factors which have a large influence on the growth potential of the population. For example, an assessment of fisheries efficiency and productivity are preliminary requirements in order to evaluate the importance of this human activity on the population and distinguish its effect from the natural causes of mortality at settlement. Unfortunately, the quantities/weight of postlarvae caught by fisheries are not subject to official declarations in La Réunion, which complicates the task of data-hungry biologists.

Despite the many pitfalls and "blind data spots" we were able to reproduce the dynamics of $S$. lagocephalus in good general agreement with our knowledge on survival, 
fecundity and seasonal patterns (i.e. the model captures age and peaks of recruitment in river mouths). The large uncertainties that remain concerning the parameter values still preclude the use of our model for projection/management purposes. Such a model would ideally lead to recommendations on preservation and conservation measures that would insure the subsistence of the local stock of S. lagocephalus. Although not mature enough to be used as a projection tool, our model has shed light on the components of the life history that are critical to the completion of the life cycle: more precise estimates of the fish's life expectancy in river and mortality at recruitment and survival during the drift of larvae toward the sea would bring the model closer to being a workable management tool. 


\begin{tabular}{|c|c|c|c|c|}
\hline Parameter & Definition & Value & Source & Corr. coeff. \\
\hline \multicolumn{5}{|c|}{ Reproductive periods } \\
\hline Downstream & Begin-End months & Nov.-July & {$[50]$} & $(0.20,-0.19)$ \\
\hline Midstream & Begin-End months & Jan.-June & {$[50]$} & $(0.15,-0.10)$ \\
\hline Upstream & Begin-End months & Fev.-May & {$[50]$} & $(0.01,-0.10)$ \\
\hline \multicolumn{5}{|c|}{ Age-specific fecundity } \\
\hline$\rho$ & Time before sexual maturation & 9 mo. & {$[48]$} & -0.05 \\
\hline$f_{\max }$ & Max fertility & 73989.71 eggs & {$[50,14]$} & 0.38 \\
\hline$f_{\min }$ & Min fertility & -31583.25 eggs & {$[50,14]$} & -0.03 \\
\hline$a_{\text {inf }}$ & Age at fertility inflection & $11.80 \mathrm{mo}$. & {$[50,14]$} & -0.16 \\
\hline$d_{\text {inf }}$ & Deriv. fertility at inflection & $3.49 \mathrm{eggs} / \mathrm{mo}$ & {$[50,14]$} & 0.07 \\
\hline \multicolumn{5}{|c|}{ Drift survival } \\
\hline$\eta$ & Probability of reaching the sea & 1 & {$[51]$} & 0.35 \\
\hline \multicolumn{5}{|c|}{ Pelagic survival } \\
\hline$\sigma_{1}$ & Larval survival rate at 2 mo. & $10^{-4}$ & {$[20,21]^{*}$} & 0.13 \\
\hline$\sigma_{2}$ & Larval survival rate at 7 mo. & $2 \times 10^{-5}$ & {$[20,21]^{*}$} & 0.21 \\
\hline$\kappa$ & Seasonal effect of temperature & 0.2 & {$[20]^{*}$} & 0.06 \\
\hline$b_{0}$ & Mesor of the periodic regression & 25.73 & {$[37]$} & \\
\hline$b_{1}$ & Periodic regression coefficient & 2.24 & {$[37]$} & \\
\hline$b_{2}$ & Periodic regression coefficient & 0.80 & {$[37]$} & \\
\hline \multicolumn{5}{|c|}{ Pelagic duration } \\
\hline$\left(\mu_{1}, \sigma_{1}\right)$ & (mean, std. dev) & $(4.37,0.76)$ & {$[48]$} & $(-0.10,0.00)$ \\
\hline$\left(\mu_{2}, \sigma_{2}\right)$ & (mean, std. dev) & $(5.14,0.78)$ & {$[48]$} & $(-0.01,0.04)$ \\
\hline$\left(\mu_{3}, \sigma_{3}\right)$ & (mean, std. dev) & $(5.38,0.91)$ & {$[48]$} & $(-0.05,0.02)$ \\
\hline$\left(\mu_{4}, \sigma_{4}\right)$ & (mean, std. dev) & $(6.31,1.00)$ & {$[48]$} & $(-0.05,0.01)$ \\
\hline$\left(\mu_{5}, \sigma_{5}\right)$ & (mean, std. dev) & $(6.71,0.86)$ & {$[48]$} & $(-0.08,-0.04)$ \\
\hline$\left(\mu_{6}, \sigma_{6}\right)$ & (mean, std. dev) & $(7.09,1.01)$ & {$[48]$} & $(-0.04,-0.01)$ \\
\hline$\left(\mu_{7}, \sigma_{7}\right)$ & (mean, std. dev) & $(7.08,0.88)$ & {$[48]$} & $(-0.02,0.01)$ \\
\hline$\left(\mu_{8}, \sigma_{8}\right)$ & (mean, std. dev) & $(6.80,0.84)$ & {$[48]$} & $(0.04,0.01)$ \\
\hline$\left(\mu_{9}, \sigma_{9}\right)$ & (mean, std. dev) & $(6.05,0.65)$ & {$[48]$} & $(-0.01,0.00)$ \\
\hline$\left(\mu_{10}, \sigma_{10}\right)$ & (mean, std. dev) & $(4.79,1.01)$ & {$[48]$} & $(0.02,-0.02)$ \\
\hline$\left(\mu_{11}, \sigma_{11}\right)$ & (mean, std. dev) & $(4.28,0.35)$ & {$[48]$} & $(0.00,0.04)$ \\
\hline$\left(\mu_{12}, \sigma_{12}\right)$ & (mean, std. dev) & $(4.48,0.78)$ & {$[48]$} & $(-0.05,0.01)$ \\
\hline \multicolumn{5}{|c|}{ Recruitment survival and site-dispersion } \\
\hline & Survival rate at recruitment & 0.05 & {$[13,28]^{*}$} & 0.35 \\
\hline$\left(\theta_{1}, \theta_{2}\right)$ & $\begin{array}{l}\text { Probabilities of river-site choice } \\
\left(\theta_{3}=1-\left(\theta_{1}+\theta_{2}\right)\right)\end{array}$ & $(0.55,0.35)$ & {$[40]$} & $(0.07,0.03)$ \\
\hline \multicolumn{5}{|c|}{ River survival } \\
\hline$e$ & Life expectancy & $24 \mathrm{mo}$. & {$[7,23]^{*}$} & 0.58 \\
\hline
\end{tabular}

Table 1: Parameter descriptions, their baseline values and sources (*: studies dealing with species close to Sicyopterus lagocephalus). The last column has the estimated Pearson correlation coefficients. 


\section{Acknowledgments}

We thank an anonymous referee for useful comments on a previous version of this paper.

We are thankful to the ARDA staff for their help and commitment: Pierre Bosc (director), Raphael Lagarde and Henry Grondin.

The present study was conducted with the financial support of the European Union (European Regional Development Fund and European Social Fund), Région Réunion (Avenue René Cassin, BP 7190, 97719 Saint Denis cedex 9) and Electricité De France (22-30 avenue de Wagram, 75382 Paris Cedex 8).

\section{References}

[1] A. Aboussouan, Note sur les "bichiques" de l'île de la réunion, Revue des travaux de la station marine d'Endoume (1969) 25-31.

[2] K.N.I. Bell, Life cycle, early life history, fisheries and recruitment dynamics of Diadromous gobies of Dominica, W.I., emphasising Sicydium punctatum Perugia, PhD thesis, Biology Department, Memorial University of Newfoundland St. John's, Canada, 275 p., 1994.

[3] K.N.I. Bell, An overview of goby-fry fisheries, Naga Manila 22 (1999) 30-36.

[4] K.N.I. Bell, P. Pepin, J.A. Brown, Seasonal, inverse cycling of length and age-at recruitment in the diadromous gobies Sicydium punctatum and Sicydium antillarum in Dominica, West-Indies, Can. J. Fish. Aquat. Sci. 52 (1995) 1535-1545.

[5] C.I. Bliss, Periodic regression in biology and climatology, Connecticut Agricultural Experimental Station, Bulletin 615, New Haven, 64 p., 1958

[6] R.W. Blob, R. Rai, M.L. Julius, H.L. Schoenfuss, Functional diversity in extreme environments: effects of locomotor style and substrate texture on the waterfall climbing performance of Hawaiian gobiid fishes, J. Zool. 268 (2006) 315-324.

[7] R.W. Blob, S. M. Kawano, K. N. Moody, W. C. Bridges, T. Maie, M. B. Ptacek, M. L. Julius, H. L. Schoenfuss, Morphological selection and the evaluation of potential tradeoffs between escape from predators and the climbing of waterfalls in the Hawaiian stream goby Sicyopterus stimpsoni, Integr. Comp. Biol. 50 (2010) 1185-1199.

[8] F. Campolongo, A. Saltelli et J.Cariboni. From screening to quantitative sensitivity analysis. A unified approach. Computer Physics Communications, 182 (2011) 978988.

[9] J. Cariboni, D. Gatelli, R. Liska et al. The role of sensitivity analysis in ecological modelling. Ecocological Modelling, 203 (2007) 167-182.

[10] H. Caswell, Matrix population models: Construction, Analysis and Interpretation. Second edition. Sinauer Associates, Sunderland, Massachusetts, USA, 2001.

[11] H. Caswell, Sensitivity and elasticity of density-dependent population models. Journal of Difference Equations and Applications 15 (2009) 349-369. 
[12] H. Caswell, Matrix models and sensitivity analysis of populations classified by age and stage: a vec-permutation matrix approach. Theoretical Ecol 5 (2012) 403-417.

[13] P. Chabanet, M. Moyne-Picard, K. Pothin, Cyclones as mass settlement vehicles for groupers. Coral Reefs 24(1) (2005) 138.

[14] P. Delacroix, Etude des bichiques, juvéniles de Sicyopterus lagocephalus (Pallas), poisson Gobiidae, migrateur des rivières de La Réunion (Océan Indien): exploitation, répartition, biologie de la reproduction et de la croissance, PhD Thesis, University of La Réunion, France, 1987.

[15] P. Ha, III. R.A. Kinzie, Reproductive biology of Awaous guamensis, an amphidromous Hawaiian goby, Env. Biol. Fish. 48 (1996) 383-396.

[16] D.M. Hamby, A review of techniques for parameter sensitivity analysis of environmental models, Environmental Monitoring and Assessment, 32 (1994) 135-154.

[17] J.C. Helton, J.D. Johnson, C.J. Sallaberry et. al. Survey of sampling-based methods for uncertainty and sensitivity analysis. Reliability Engineering and System Safety, 91 (2006) 1175-1209.

[18] T. Hoareau, Dynamique structurale des populations de bichiques (Sicyopterus lagocephalus), Gobiidae amphidromes des rivières de La Réunion. PhD Thesis, University of La Réunion, France, 2005.

[19] T. Hoareau, R. Lecomte-Finiger, H.P. Grondin, C. Conand, P. Berrebi, Oceanic larval life of La Réunion 'bichiques', amphidromous gobiid post-larvae, Mar. Ecol. Prog. Ser. 333 (2007) 303-308.

[20] E.D. Houde, Comparative Growth, Mortality, and Energetics of Marine Fish Larvae: Temperature and Implied Latitudinal Effects, Fish. Bull. 87(3) (1989) 471-495.

[21] E.D. Houde, Patterns and trends in larval-stage growth and mortality of teleost fish. J. Fish Biol. 51(A) (1997) 52-83.

[22] M. Iida, S. Watanabe, K. Tsukamoto, Reproductive biology of an amphidromous goby Sicyopterus japonicus (Gobiidae: Sicydiinae), Cybium 35(4) (2011) 329-336.

[23] M. Iida, S. Watanabe, K. Tsukamoto, Riverine life history of the amphidromous goby Sicyopterus japonicus (Gobiidae: Sicydiinae) in the Ota River, Wakayama, Japan, Env. Biol. Fish. 96(5) (2013) 645-660.

[24] A.P. Jenkins, S.D. Jupiter, I. Qauqau, J. Atherton The importance of ecosystembased management for conserving aquatic migratory pathways on tropical high islands: a case study from Fiji, Aquat. Conserv. 20 (2009) 224-238.

[25] P. Keith, Biology and ecology of amphidromous Gobiidae of the Indo-Pacific and the Caribbean regions, J. Fish Biol. 63 (2003) 831-847.

[26] P. Keith, T.B. Hoareau, C. Lord, O. Ah-Yane, G. Gimonneau, T. Robinet, P. Valade, Characterisation of post-larval to juvenile stages, metamorphosis and recruitment of an amphidromous goby, Sicyopterus lagocephalus (Pallas) (Teleostei: Gobiidae: Sicydiinae), Mar. Freshw. Res. 59(10) (2008) 876-889. 
[27] M. Lesnoff, P. Ezanno, H. Caswell. Sensitivity analysis in periodic matrix models: a postscript to Caswell and Trevisan. Applied Mathematics Letters: Mathematical and Computer Modelling 37 (2003) 945-948.

[28] Y. Letourneur, P. Chabanet, L. Vigliola, M. Harmelin-Vivien, Mass Settlement and Post-Settlement Mortality of Epinephelus Merra (Pisces: Serranidae) On Réunion Coral Reefs, J. Mar. Biol. Ass. U. K. 78 (1998) 307-319.

[29] C. Lord, C. Brun, M. Hautecoeur, P. Keith, Comparison of the duration of the marine larval phase estimated by otolith microstructural analysis of three amphidromous Sicyopterus species (Gobiidae: Sicydiinae) from Vanuatu and New Caledonia: insights on endemism, Ecol. Freshw. fish 19 (2010) 26-38.

[30] C. Lord, J. Lorion, A. Dettai, S. Watanabe, K. Tsukamoto, C. Cruaud, P. Keith, From endemism to widespread distribution: phylogeography of three amphidromous Sicyopterus species (Teleostei: Gobioidei: Sicydiinae), Mar. Ecol. Prog. Ser. 455 (2012) 269-285.

[31] P.R. Manacop, The life history and habits of the goby, Sicyopterus extraneus Herre (Anga) Gobiidae with an account of the goby fry fishery of Cagayan River, Oriental Misamis, Philipp. J. Fish. 2 (1953) 1-60.

[32] R.M. McDowall, Seasonal pulses in migrations of New Zealand diadromous fish and the potential impacts of river mouth closure, N. Z. J. Mar. Freshw. Res. 29 (1995) 517-526.

[33] R.M. McDowall, Diadromy and the assembly and restoration of riverine fish communities: A downstream view. Canadian journal of fisheries and aquatic sciences, Can. J. Fish. Aquat. Sci. 53 (1996) 219-236.

[34] R.M. McDowall, On amphidromy, a distinct form of diadromy in aquatic organisms, Fish Fish. 8 (2007) 1-13.

[35] R.M. McDowall, Why be amphidromous: expatrial dispersal and the place of source and sink population dynamics?, Rev. Fish Biol. Fisher. 20 (2010) 87-100.

[36] M.J. Myers, Usage of anadromous, catadromous and allied terms for migratory fishes, Copeia (1949) 89-97.

[37] NOAA Coral Reef Watch. 2000, updated twice-weekly. NOAA Coral Reef Watch 50$\mathrm{km}$ Satellite Virtual Station Time Series Data for Reunion Island, Jan. 1, 2006-Dec. 31, 2008. Silver Spring, Maryland, USA: NOAA Coral Reef Watch. Data set accessed 2011-04-01 at http://coralreefwatch.noaa.gov/satellite/vs/index.html

[38] T.J. Quinn, R.B. Deriso, Quantitative Fish Dynamics, Oxford University Press, USA, 1999

[39] A. Ramírez, A. Engman, K.G. Rosas, O. Perez-Reyes, D.M. Martinó-Cardona, Urban impacts on tropical island streams: Some key aspects influencing ecosystem response, Urban Ecost. 15 (2012) 315-325. 
[40] M. Richarson, P. Valade, H. Grondin H, Synthèse du Réseau Piscicole de La Réunion en 2007, Technical report ARDA, DIREN, ONEMA, Région Réunion, Département de la Réunion, France, 2008.

[41] R.J. Rolls, The role of life-history and location of barriers to migration in the spatial distribution and conservation of fish assemblages in a coastal river system, Biol. Conserv. 144 (2011) 339-349.

[42] A. Saltelli, S. Tarantola. On the relative importance of input factors in mathematical models: Safety assessment for nuclear waste disposal. Journal of the American Statistical Association, 97 (2002) 702-709.

[43] A. Saltelli, M. Ratto, S. Tarantola et F.Campolongo. Sensitivity analysis practices: Strategies for model-based inference. Reliability Engineering and System Safety, 91 (2006) 1109-1125.

[44] A. Schübel, Pêcheurs de bichique à la Réunion. Graduate Report. Idea Consultants, La Possession, La Réunion, 1998.

[45] K.N. Shen, W.N. Tzeng, Reproductive strategy and recruitment dynamics of amphidromous goby Sicyopterus japonicus as revealed by otolith microstructure, J. Fish Biol. 73(10) (2008) 2497-2512.

[46] I.M. Sobol. Global sensitivity indices for nonlinear mathematical models and their Monte-Carlo estimates. Mathematics and computer in Simulation, 55 (2001) 271-280.

[47] S. Tarantola, D. Gatelli, T.A. Mara, Random balance designs for the estimation of first order global sensitivity indices, Reliability Engineering and System Safety 91 (2006) 717-727.

[48] N. Teichert, Variability of life history traits of two amphidromous Gobiidae (Sicydiinae) in Reunion Island: Sicyopterus lagocephalus (Pallas, 1770) and Cotylopus acutipinnis (Guichenot, 1863), PhD Thesis, University of Pau and Pays de l'Adour, France, 2012.

[49] N. Teichert, P. Valade, P. Lim, F. Dauba, J. Labonne, M. Richarson, P. Bosc, P. Gaudin, 2013. Habitat selection in amphidromous Gobiidae of Reunion Island: Sicyopterus lagocephalus (Pallas, 1770) and Cotylopus acutipinnis (Guichenot, 1863), Env. Biol. Fish. DOI 10.1007/s10641-013-0148-0.

[50] N. Teichert, P. Valade, A. Fostier, R. Lagarde, P. Gaudin, Reproductive biology of an amphidromous goby, Sicyopterus lagocephalus, in La Réunion Island, Hydrobiologia 726(1) (2014) 123-141.

[51] P. Valade, C. Lord, H. Grondin, P. Bosc, L. Taillebois, M. Iida, K. Tsukamoto, P. Keith, Early life history and description of larval stages of an amphidromous goby, Sicyopterus lagocephalus (Gobioidei: Sicydiinae). Cybium 33 (2009) 309-319. 